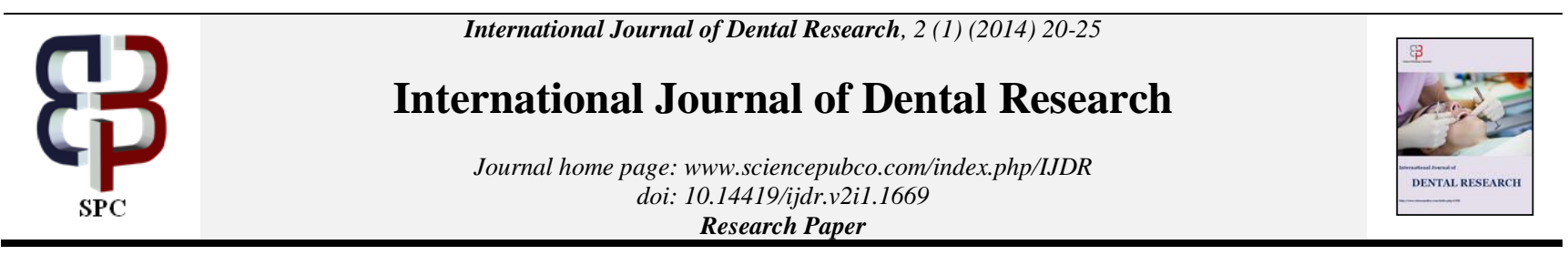

\title{
Association of complete denture wearing with the rate of reduction of mandibular residual ridge using digital panoramic radiography
}

\author{
Osama Al-Jabrah ${ }^{1 *}$, Yousef Al-Shumailan ${ }^{2}$ \\ Division of Prosthetic Dentistry, Department of Dentistry, King Hussein Medical Center, Royal Medical Services, Amman, Jordan \\ *Corresponding author E-mail: osamajabrah@hotmail.com
}

\begin{abstract}
Background: Residual ridge reduction is one of the main causes of loss of stability and retention of mandibular complete dentures. The severity of bone loss is very important clinical condition facing the aging population.

Objectives: To investigate the association of the mandibular ridge reduction with duration of complete denture wearing in relation to age and gender is using digital panoramic radiography.

Methods: Seventy-five (40 men and 35 women) with a mean age $66.21 \pm 10.21$ years, denture-wearing patients were included in this study. Resorption in the mandibular residual ridges was assessed by using the mental foramen and the inferior border of the mandible, as they appear in digital panoramic radiographs, using Wical and Swoope Analysis method. Measurements were performed digitally using Sidexis next Generation software. The amount of resorption was calculated and correlated to gender, age and duration of denture wearing. Statistical analysis was performed using SPSS (V17.0). Level of significance was set at 0.05 .

Results: The mean ridge resorption was $7.74 \pm 5.80 \mathrm{~mm}(20 \%)$, Women significantly $(\mathrm{P}<0.05)$.recoded more resorption than men (women: men ratio was $3: 2)$. Men significantly $(\mathrm{P}<0.0001)$ had greater mandibular ridge and mental foramen heights than women. Ridge resorption significantly increased with increasing age $(\mathrm{P}<0.0001)$ and duration of denture wearing $(\mathrm{P}<0.001)$. Women significantly $(\mathrm{P}<0.05)$ had greater ridge resorption than men below 50 and above 80 years old; and in all denture wearing duration groups.

Conclusion: Reduced mandibular height is directly related to age and duration of complete denture wearing. Women are at more risk to have ridge resorption compared to men.
\end{abstract}

Keywords: Complete denture, mandible, mental foramen, panoramic radiography, residual ridge resorption.

\section{Introduction}

Residual ridge resorption (RRR) is a continuous process of alveolar bone loss, which is greater during the first few months after the tooth extraction than later (Kovacic et al. 2012). The rate of resorption is twice more pronounced in the mandible than in the maxilla Tallgren 2003. Progressive ridge resorption is one of the main causes of loss of stability and retention of mandibular complete dentures (Zlataric \& Celebic 2003).

The severity of bone loss and high incidence of RRR are are highly associated with osteoporosis [Bianchi \& Sanfilippo (2002), Watanabe et al. (2007), Canger \& Celenk (2012)] increases with the advance of age (Jagadeesh et al. 2013) and favors the female sex for predisposition [Sakar et al. (2008), Vaishnav et al. (2010)]. Numerous investigators have made an attempt to analyze the changes in the form of the residual alveolar ridge using lateral cephalograms [Spoyler (1987), Atwood (1996)], denture relining procedure (Kranjcic et al. 2013), diagnostic casts (Ozola et al. 2011), or dry adult mandibles (Saini et al. 2011). In addition, panoramic radiographs (OPG) were extensively utilized by several investigators [Stramotas et al. (2002), Arifin et al. (2005), LópezRoldán et al. (2009), Shahabi et al. (2009), Huumonen et al. (2010), Al-Shamout et al. (2012)], because they have greater area of hard and soft tissue and the ability to visualize adjacent areas, thus allowing for a more accurate localization of the mental for a men in both the horizontal and vertical dimensions [Balcikonyte et al. (2003), Kordatzis et al. (2003), Juodzbalys et al. (2010), AlJabrah (2011)].

Wical and Swoope method is one of the widely used methods to determine the amount of RRR on orthopantomogram (Wical \& Swoope 1974). It is simple, useful method for arriving at a gross estimate of the amount of RRR in a given patient at that particular time [Amorim et al. (2008), Ngeow et al. (2009)].

The aims of this study were to assess the amount of mandibular RRR in edentulous patients wearing CDs and to evaluate the association of RRR with duration of denture wearing in relation to age and gender.

\section{Materials and methods}

\subsection{Ethical approval}

The study protocol was approved by the Head of Dental Specialty in the Department of Dentistry and Ethical Committees of the Royal Medical services.

\subsection{Patients}

The original sample of this cross-sectional study was selected from a general population of completely edentulous subjects who 
attended (or referred to) Prosthodontic clinic; Dental Department, Prince Ali Bin Al-Hussien hospital in Karak, Jordan; for replacement of their missing teeth with (or maintenance of existing) complete dentures The study sample consisted of 75 (40 men and 35 women) subjects with a mean age of $66.21 \pm 10.21$ years (ranged between 40 and 83 years) complete denture wearers were selected and accepted to participate in this study.

\subsection{Inclusion/exclusion criteria}

The selected subjects had not undergone prosthetic surgical procedures (i.e. sulcus deepening or ridge augmentation). They were completely edentulous with no systemic bone disease and not less than one year post-tooth extraction period. Only clear OPGs with visible structures for the measurements were included in this study. None of the subjects had any metabolic bone disease, cancers with bone metastasis, significant renal impairment and had medications with affect bone metabolism, such as estrogen.

\subsection{Clinical and radiographic examinations}

The data were obtained by using an interview (including general health and self-reported diseases), as well as clinical and radiographic examination. All subjects gave verbal consent to participate in the study and accepted to undergo radiographical examination. Clinical examination was carried out on the dental chair with the patient seated in an upright position, and the head was in the natural position, it was performed by one prosthodontists examiner. Thereafter, a digital OPG was taken using Orthophos XG Plus (Model: 5884999d3352, SN: 03024, Sirona, Siemens, Germany). All OPGs were performed by one trained dental radiology technician. The exposure parameters $64 \mathrm{kV}$ and $8 \mathrm{~mA}$ were selected and the mean resolution of the original OPGs was $1744 \times 3158$ pixels. All digital OPGs were measured digitally using Sidexis next Generation software (Version 1.52; Sirona, Siemens, Germany), on Dell Inspiron (N 5010, China) personal computer. Measurements were performed by one Prosthodontist's examiner who used the same reference points required for obtaining the measurements of the linear distances on each OPG. For each parameter, 3 readings were taken and the mean was calculated.

\subsection{Measurements}

Mandibular RRR was assessed by using the mental foramen and the inferior border of the mandible, as they appear in OPGs, as reference points using Wical and Swoope Analysis method; in which the original height of the mandible is assumed to be three times the distance between the inferior border of the mandible to the lower border of the mental foramen [Wical \& Swoope (1974), Atwood (1996)]. The amount of mandibular ridge resorption (R) was estimated from the original mandibular alveolar level to the measured level of the residual ridge $(\mathrm{L})$ was expressed as a percentage of the original height of the mandible (Fig. 1). The amount of resorption was calculated according to the formula: $\mathrm{R}=3 \mathrm{x}-\mathrm{L}$, (where R: amount of mandibular RRR; $\mathrm{x}$ : distance from inferior border of mandible to the lower border of mental foramen; L: height of mandibular residual alveolar ridge). The measuring error was set to $\pm 0.01 \mathrm{~mm}$ for specific measured dimensions on each OPG. Measurements were performed on the right side, and the mean value and standard deviation were calculated. The amount of mandibular RRR was calculated and correlated with duration of wearing complete dentures. Gender and age differences were also investigated and correlated to RRR and duration of complete denture wearing.

\subsection{Statistical analysis}

Statistical analysis was performed using (SPSS-v17.0 Inc., Chicago, Ill., USA). Multiple linear regression analysis was performed to test the interaction between variables in the model (gender, age and years of denture wearing) and ridge height of the mandible.
Paired samples t-test was carried out to compare between the right and left sides and gender differences in the mean values of RRR. Wilcoxon Signed Ranks Test was used to test the correlation between mandibular residual ridge resorption and age of participants and duration of denture wearing. Paired (Independent samples 2tailed) Student's t-test was used to compare the means of each participant's age group and complete denture wearing duration with the amount of mandibular RRR between men and women. Level of significance was set to 0.05 .

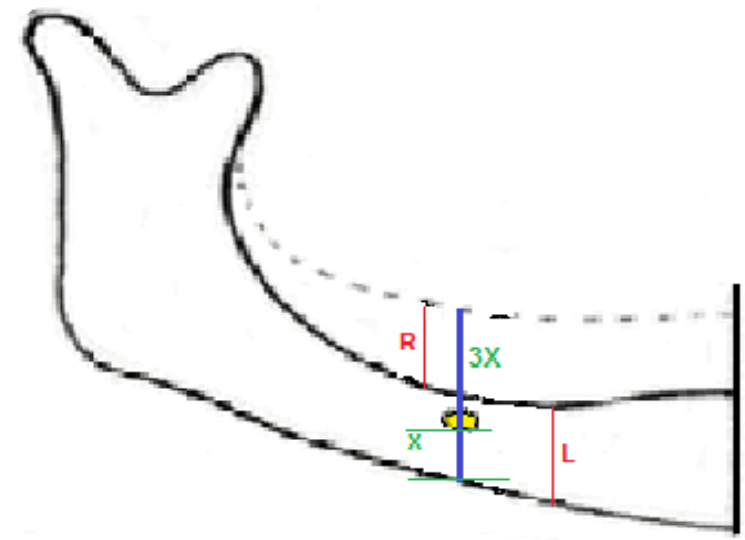

Fig. 1: Schematic drawing showing Wical and Swoope analysis method used in the study. $(R=3 x-L)$.

(R: mandibular ridge resorption; $\mathrm{x}$ : vertical linear distance measured from inferior border of the mandible to the inferior border of the mental foramen; L: vertical linear distance of actual ridge height measured across the mental foramen; 3 xs: original vertical ridge height across the mental foramen before resorption).

\section{Results}

Variability and bias in measurements between right and left sides were assessed by re-measuring distances $\mathrm{x}$ : (inferior border of mandible-mental foramen) and L: (the height of mandibular residual ridge across the mental foramen) on 19 (25.3\%) randomly selected OPGs on the left side of 9 women and 10 men. Paired Student's t-test was performed to unveil statistically significant deviation of measurements between right and left sides, (the mean difference was $-0.0526 \pm 0.310 \mathrm{~mm}$; $\mathrm{t}$-test $=-0.741 ; \mathrm{P}$ value $=0.468$ for differences in $\mathrm{x}$ distance; and mean difference of 2.038 \pm 8.94 ; $\mathrm{t}$-test $=0.994, \mathrm{P}$ value $=0.333$ for differences in $\mathrm{L}$ distance). As there were strong correlation coefficient $(0.990$ and 0.505 for $\mathrm{x}$ and L distances; respectively), and small mean difference between the two-side measurements, it was assumed that the right side measurements would be reliable.

Multiple linear regression analysis was performed to test the interaction between variables in the model (gender, age and years of denture wearing) and ridge height of the mandible. Statistically significant interaction between gender, age and denture wearing duration and RRR were recorded (Table 1).

Table 2 shows gender differences in the mean (SD) values of age of participants, duration of complete denture wearing, measurements of actual height of mandibular alveolar residual ridge and height of mental foramen and mean and percentage of mandibular RRR. Men significantly recorded higher mean values of mandibular alveolar residual ridge ( $\mathrm{P} \square 0.0001)$ and height of mental foramen ( $\mathrm{P} \square 0.0001)$ compared to women. The mean of mandibular RRR in the study sample was $7.74 \pm 5.80 \mathrm{~mm}$ (approximately $20 \%$ ). Women recoded higher mean value of RRR compared to men (women: men ratio was approximately $3: 2$ ), this gender difference was statistically significant (t-test=2.275; P-value $\square 0.05$ ). The results of Wilcoxon signed ranks test showed that RRR significantly increased with increasing age of participants $(Z=-7.525$; $\mathrm{P}<0.0001)$ and duration of denture wearing $(\mathrm{Z}=-2.870 ; \mathrm{P}<0.001)$. Table 3.

Paired sample t-test was performed to reveal whether if there were any statistically significant differences in the percentages of man- 
dibular RRR between men and women for each participants' age group (Table 4) and complete denture wearing duration group (Table 5), or not. Table 4 shows that statistically significant gender differences in mandibular RRR in participants below 50 and above 80 years old. Women significantly $(\mathrm{P}<0.05)$ had mandibular RRR of $7.01 \%$ and $57.12 \%$ compared to men who had $1.92 \%$ and $29.68 \%$, for age groups below 50 and above 80 years. However; for the remaining middle age groups, although women had more amount of RRR than men, but the differences were statistically insignificant. Table 5 shows that there were direct relationship between mandibular RRR and complete denture wearing duration. The more the years of complete denture wearing, the more the mandibular RRR. In addition, women significantly $(\mathrm{P}<0.05)$ had more amount of mandibular RRR compared to men in all denture wearing duration groups.

Table 1: Results of linear regression analysis

\begin{tabular}{|c|c|c|c|c|c|}
\hline Variable & Coefficient & Standard error & $\mathrm{t}$ & $95 \%$ Confidence interval & $\mathrm{P}$ value \\
\hline Gender & 0.069 & 0.021 & 4.006 & 0.002 to 0.109 & 0.000 \\
\hline Age & -0.091 & 0.009 & -5.231 & -0.118 to -0.062 & 0.000 \\
\hline $\begin{array}{l}\text { complete denture } \\
\text { wearing duration }\end{array}$ & -0.001 & 0.000 & -2.029 & -0.004 to 0.0065 & 0.039 \\
\hline
\end{tabular}

Table 2: Gender differences in the mean (SD) values of mandibular residual ridge resorption $(R=3 x-L)$ in relation to age and duration of denture wearing (Paired samples t-test).

\begin{tabular}{|c|c|c|c|c|c|c|c|}
\hline & Participants' age & $\begin{array}{c}\text { Complete denture } \\
\text { age }\end{array}$ & $\mathrm{x}$ & $3 x$ & $\mathrm{~L}$ & \multicolumn{2}{|c|}{$\mathrm{R}$} \\
\hline & \multicolumn{2}{|c|}{ (in Years) } & & (in $\mathrm{mm}$ ) & & (in $\mathrm{mm}$ ) & $(\operatorname{In} \%)$ \\
\hline Women $(n=35)$ & $65.71(10.55)$ & $9.06(8.11)$ & $12.08(1.97)$ & $36.23(5.91)$ & $27.35(6.67)$ & $8.89(6.89)$ & $\begin{array}{c}24.03 \\
(16.43)\end{array}$ \\
\hline Men $(n=40)$ & $66.65(10.02)$ & $9.15(6.64)$ & $14.06(1.80)$ & $42.19(5.40)$ & $35.45(7.11)$ & $6.74(4.49)$ & $\begin{array}{c}16.28 \\
(10.85)\end{array}$ \\
\hline Overall $(n=75)$ & $66.21(10.21)$ & $9.11(7.31)$ & $13.14(2.12)$ & $39.41(6.35)$ & $31.67(8.01)$ & $7.74(5.80)$ & $\begin{array}{c}19.89 \\
(14.18)\end{array}$ \\
\hline $\mathrm{P}$-value & $0.477(\mathrm{NS})$ & $0.744(\mathrm{NS})$ & \multicolumn{2}{|c|}{0.000} & 0.000 & \multicolumn{2}{|c|}{0.029} \\
\hline
\end{tabular}

$\mathrm{X}$ : measured distance from inferior border of mandible to inferior border of mental foramen, 3x: calculated original mandibular ridge height, L: measured height of mandibular residual ridge, R: residual ridge resorption (calculated), NS: not significant.

Table 3: Correlation between mandibular residual ridge resorption and age of participants and duration of denture wearing (Wilcoxon Signed Ranks Test).

\begin{tabular}{|c|c|c|c|c|c|c|}
\hline \multirow[b]{2}{*}{ Age range } & \multicolumn{4}{|c|}{ Correlation (age versus resorption) } & \multicolumn{2}{|c|}{ Wilcoxon Test } \\
\hline & $\mathrm{n}$ & Age & Resorption (\%) & denture age & $Z^{*}$ & P-value** \\
\hline$<50$ & 5 & $44.60(2.88)$ & $4.97(3.93)$ & $1.20(0.45)$ & & \\
\hline $50-59$ & 14 & $55.43(2.56)$ & $8.63(5.03)$ & $3.14(2.25)$ & & \\
\hline $70-79$ & 26 & $74.50(3.05)$ & $27.69(14.24)$ & $12.89(7.32)$ & & \\
\hline$\geq 80$ & 6 & $81.67(1.37)$ & $38.83(15.38)$ & $22.00(3.90)$ & & \\
\hline \multicolumn{7}{|c|}{ Correlation (denture age versus resorption) } \\
\hline Denture age range & $\mathrm{n}$ & & & & & \\
\hline$<5$ & 28 & $58.79(9.85)$ & $7.91(4.24)$ & $2.50(1.04)$ & & \\
\hline $5-9$ & 16 & $65.06(4.89)$ & $15.73(6.87)$ & $6.63(1.31)$ & & \\
\hline $10-14$ & 12 & $67.67(7.28)$ & $24.79(4.42)$ & $11.17(1.53)$ & & \\
\hline $15-19$ & 10 & $75.70(3.92)$ & $32.99(10.31)$ & $15.90(1.29)$ & $-2.8 / 0$ & 0.004 \\
\hline $20-24$ & 5 & $79.40(3.51)$ & $42.86(13.47)$ & $21.40(1.34)$ & & \\
\hline$\geq 25$ & 4 & $78.50(3.11)$ & $44.31(12.47)$ & $26.75(2.36)$ & & \\
\hline Overall & & $66.21(10.21)$ & $19.89(14.18)$ & $9.11(7.31)$ & & \\
\hline
\end{tabular}

* Based on negative ranks, ** Sig. (2-tailed)

Table 4: Correlation of participants'age with the amount of mandibular residual ridge resorption in relation to gender. (Paired Samples Test)

\begin{tabular}{|c|c|c|c|c|c|c|c|c|c|}
\hline \multirow{2}{*}{ Age range* } & \multicolumn{3}{|c|}{ Women } & \multicolumn{3}{|c|}{ Men } & \multicolumn{3}{|c|}{ Paired Samples Test } \\
\hline & $\mathrm{n}$ & Age & Resorption (\%) & $\mathrm{n}$ & Age & Resorption (\%) & df & t-test & P-value \\
\hline$<50$ & 3 & $43.67(3.51)$ & $7.01(3.58)$ & 2 & $46.00(1.41)$ & $1.92(2.22)$ & 1 & 4.154 & 0.032 \\
\hline $50-59$ & 6 & $55.00(3.35)$ & $11.06(3.16)$ & 8 & $55.75(1.98)$ & $6.39(5.15)$ & 5 & 2.124 & 0.055 (NS) \\
\hline $70-79$ & 13 & $74.31(3.28)$ & 33.24 16.06) & 13 & $74.69(2.93)$ & $22.14(9.88)$ & 12 & 1.291 & 0.253 (NS) \\
\hline$\geq 80$ & 2 & $81.00(1.41)$ & $57.12(1.30)$ & 4 & $82.00(1.41)$ & $29.68(7.70)$ & 1 & 3.068 & 0.0455 \\
\hline Total & 35 & $65.71(10.55)$ & $24.03(16.43)$ & 40 & $66.65(10.02)$ & $16.28(10.85)$ & 34 & 2.275 & 0.029 \\
\hline
\end{tabular}

* Women age range: 40-82; Men age range: 45-83; NS: not significant

Table 5: Correlation of complete denture wearing duration with the amount of mandibular residual ridge resorption between men and women. (Paired Samples Test)

\begin{tabular}{|c|c|c|c|c|c|c|c|c|c|}
\hline & \multicolumn{3}{|c|}{ Women } & \multicolumn{3}{|c|}{ Men } & \multicolumn{3}{|c|}{ Paired Samples Test } \\
\hline CDWD* range & $\mathrm{n}$ & $\mathrm{CDWD}^{*}$ & Resorption (\%) & $\mathrm{n}$ & CDWD* $^{*}$ & Resorption (\%) & df & t-test & $\mathrm{P}$-value \\
\hline$<5$ & 15 & $2.53(0.99)$ & $10.26(3.82)$ & 13 & $2.46(1.13)$ & $5.19(3.91)$ & 14 & 8.384 & 0.000 \\
\hline $5-9$ & 8 & $6.75(1.28)$ & $20.82(3.77)$ & 8 & $6.50(1.41)$ & $10.64(5.28)$ & 7 & 4.973 & 0.002 \\
\hline $15-19$ & 3 & $16.00(1.73)$ & $44.26(12.29)$ & 7 & $15.86(1.21)$ & $28.17(4.30)$ & 6 & 4.207 & 0.006 \\
\hline $20-24$ & 3 & $20.67(1.15)$ & $50.08(5.75)$ & 2 & $22.50(0.71)$ & $31.83(12.60)$ & 2 & 8.173 & 0.015 \\
\hline$\geq 25$ & 3 & $26.67(2.89)$ & $50.22(8.99)$ & 1 & $27.00(0.00)$ & $27.00(0.00)$ & 2 & 6.955 & 0.020 \\
\hline Total & 35 & $9.06(8.11)$ & $24.03(16.43)$ & 40 & $9.15(6.64)$ & $16.28(10.85)$ & 34 & 2.275 & 0.029 \\
\hline
\end{tabular}

* CDWD: Complete denture wearing duration (in years) 


\section{Discussion}

Alveolar ridge resorption after teeth extraction is a chronic, progressive and cumulative disease of bone reconstruction. Extensive RRR is one of the many problems in prosthetic dentistry rehabilitation (Nahri et al 1997). One of the advantages of this study was that there were not gender differences in the mean age of participants and duration of $\mathrm{CD}$ wearing, thus comparing the mean values of RRR between men and women would minimize the effect of these two factors on the results.

It was observed that mandibular RRR affected all the edentulous patients in the study group to varying extents (ranged between $2 \%-57 \%$ ). The mean amount of RRR was approximately $20 \%$, $(7.74 \pm 5.80 \mathrm{~mm})$ in subjects with age ranged between 45 to 82 years wearing $\mathrm{CDs}$ for a period ranged between one and 30 years. Similar results were reported by Karaagaçloglu \& Ozkan (1994); however, some studies reported different results, Kovacic et al (2012) reported low rate of resorption $(8 \%)$ while Zmysłowska et al. (2007) reported high rate of RRR (45\%). The differences in these findings may be explained by differences in race, study samples and method of radiography and measurements.

Many local and systemic factors are associated with RRR (Kingsmil 1997). Of these, patient's age, gender and duration of denture wearing may cause resorptive changes in the edentulous parts of the maxilla and mandible (D'Souza et al. 2012). The results of linear regression analyses revealed that RRR significantly correlated with increasing age, $\mathrm{CD}$ wearing duration and between genders. Although numerous previous studies confirmed these findings [Bianchi \& Sanfilippo (2002), Al-Jabrah (2011), Canger \& Celenk (2012), Jagadeesh et al. (2013)], few studies reported no association between RRR and duration of CD wearing [Xie et al (1997), Kordatzis et al. (2003)] and age (Lopez-Roldan et al. 2009).

In the present study, gender-related differences were recorded in both groups. Women had significantly greater amount of mandibular RRR compared with men ( $24 \%$ and $16.3 \%$; respectively). In addition, men significantly had higher mental foramen and mandibular body height than women. These findings are supported by Amorim et al. (2008) who reported that males had significantly wider arches than females, and that they had larger mandibular measurements than females. In addition, Watanabe et al. (2007) reported that males presented a more strongly trabecular and complex bone than females, this finding is important index to osteoporotic risk, being possible to affirm that the male bone is less probable to suffer resorptive changes. Kordatzis et al. (2003) reported that the estimated average reduction in height for conventional CD was $1.63 \mathrm{~mm}$ in 5 years and that female gender was a risk factor for greater resorption. In their study, they found that a male patient was likely to lose $7.5 \%$ less bone $(0.9 \mathrm{~mm}$ in 5 years $)$ than a female patient of the same age. The present study showed similar findings of significant gender differences in RRR. Women had approximately $8 \%$ more resorption than men (women: men ratio was 3:2). Most of the females in the present study were past the usual age for menopause, and this may explain the genderrelated difference observed in this study. Several studies reported that females have more alveolar RRR than males [Bianchi \& Sanfilippo (2002), Kordatzis et al. (2003), Sakar et al. (2008), Lopez-Roldan et al. (2009), Al-Jabrah (2011), Canger \& Celenk (2012)]. The results of the present study have suggested that alveolar RRR is more noticeable in women. This phenomenon could be explained with the effect of the menopausal activity in women on the mandibular residual ridge. Furthermore, experimental evidence has shown that estrogen depletion leads to a significant loss of bone mass in the edentulous mandible but not in the dentate mandible [Arifin et al. (2005), Watanabe et al. (2007), Vaishnav (2010), Ozla (2011)]. Previous studies showed that women had reduced masticatory function compared with males, because women had greater amount of mandibular bone reduction which is associated with reduced cortical thickness, and resulted in reduction in bone height (Zarb et al. 1990). Conversely, some researchers have reported that mandibular bone loss observed in the eden- tulous mandible is associated with systemic diseases such as estrogen deficiency, while the maxillary bone resorption is more associated with local denture factors (Xie et al. 1997).

The results of this study revealed that the amount of mandibular RRR was significantly correlated with the number of years subjects were edentulous. Approximately, 8\% of RRR was recorded in patients who had been wearing $\mathrm{CD}$ for less than 5 years, and the rate of resorption increased in those with more years of denture wearing. The results also showed that $44.3 \%$ of the mandibular ridges had resorbed in patients who had been wearing $\mathrm{CD}$ for 20 years or more. These findings are in agreement with previous studies [Al-Jabrah (2011), Jagadeesh et al. (2013)]; However, Kordatzis et al. (2003) reported that neither number of CDs worn nor years of denture wearing are associated with RRR. The alveolar bone loss observed in denture wearers may be an inevitable consequence of the loss of natural teeth, tissue remodelling, and prolonged denture wear (Canger \& Celenk 2012) and subsequent to a long-term edentulism may be severe and the process may progress (Xie et al, 1997).

The duration of denture wearing is an influential factor in RRR between genders. Women significantly recorded greater RRR compared to men, in relation to $\mathrm{CD}$ wearing duration. Approximately $50 \%$ of RRR occurs in women wearing CD for 20 years or above. However the least amount of RRR (5\%) was recorded in men wearing $\mathrm{CD}$ for less than 5 years. These findings are in agreement with several studies [Arifin et al. (2005), Watanabe et al. (2007), Sakar et al. (2008), Al-Jabrah (2011), Ozla et al. (2011)]. In this study, the age of the subjects was significantly correlated with the amount of resorption. Young patients below the age of 50 had less than 5\% RRR, the rate of resorption increased as age increased. The greatest amount of RRR (38.8\%) was recorded in elderly patients above 80 years of age. These findings are in agreement with previous reports [Bianchi \& Sanfilippo (2002), Kordatis et al. (2003), Canger \& Celenic (2012), Jagadeesh et al. (2013)]. In addition, results showed that women significantly recorded 7\% RRR compared to $1.9 \%$ in men, in those below 50 years of age, and $57.1 \%$ compared to $29.7 \%$ in those aged 80 years or above. However, no gender differences in RRR in other age groups were recorded. Age is not an influential factor in bone loss between men and women participants 50-80 years of age. These findings were supported by Lopez-Roldan et al. (2009) who did not find a significant correlation between age and ridge resorption.

Several studies have reported that panoramic radiographs are reproducible and accurate for the linear and angular measurements on mandibles [Stramotas et al. (2002), Zlataric \& Celebic (2003), Arifin et al. (2005), Watanabe et al. (2007), Şakar et al. (2008), López-Roldán et al. (2009), Huumonen et al. (2010), Vaishnav et al. (2010), Al-Jabrah (2011), Al-Shamout et al. (2012), Canger \& Celenk (2012), Jagadeesh et al. (2013)]. The panoramic radiographs in the present study were made by one experienced dental radiographer using the same panoramic unit and all digital measurements were performed by one prosthodontist.

Mental foramen landmark selected for the present study is commonly used for studies of mandibular bone as it is fairly reproducible [Balcikonyte et al. (2003), Kordatzis et al. (2003), Arifin et al. (2005), Amorim et al. (2008), Ngeow et al. (2009), Juodzbalys et al. (2010)]. The location of the mental foramen relative to the inferior and superior borders of normal mandibles, as expressed by the mean ratio of total bone height to height of the foramen above the inferior border, appears to be a more useful reference mark and consisted enough to justify its use as a reference point in clinical studies (Shahabi et al. 2009). In this study, Wical \& Swoope (1974) method was used to evaluate the amount of mandibular RRR. Clinically, this method can help to estimate conveniently the original height of the mandible before resorption (Atwood 1996). All measurements were carried out on the right side of the OPGs; the position of mental foramen on the right side appears to be very close to those on the left side.

One of the limitation of this study was small sample size and limited participation rate, thus it does not represent Jordanian popula- 
tion as a whole. In addition, the method used gives information about RRR localized in the region of mental foramen, thus RRR in other areas is not available. Another disadvantage was that the dental status was based mainly on panoramic radiography. Therefore, the information of occlusal contacts and chewing habits were not available. Further research on a larger sample and including other factors; such as other local and systemic factors, denture quality measures and general health status may be needed before the results of this study can be applied on the general population.

The results of this study highlight on the association between duration of $\mathrm{CD}$ wearing and $\mathrm{RRR}$ in relation to age and gender. It can now be confirmed that women in particular, are at greater risk of RRR than men. Basker \& Davenport (2002) has shown that the amount of bone resorption in edentulous area is eight times than that in dentate area in the same subject. Therefore, every effort should be taken to retain natural teeth to the longest time possible as the amount of resorption would increase following teeth loss (Schwartz-Dabney \& Dechow 2002) and with increasing CD wearing period (Jagadeesh et al. 2013).

\section{Conclusion}

The mandibular ridge resorption affected all the edentulous patients to varying extents ranged between $2 \%$ and $57 \%$, with mean rate of approximately $20 \%$.

The resorption significantly increased with increasing age of participants $(\mathrm{P}<0.0001)$ and duration of denture wearing $(\mathrm{P}<0.001)$. Women significantly $(\mathrm{P}<0.05)$ recoded higher ridge resorption compared to men with approximately $3: 2$ women to men ratio.

\section{Acknowledgement}

We would like to thank Dr. Raghda Al-Shamout for her continuous help in performing statistical analysis of data and preparing the manuscript.

\section{References}

[1] Kovacic I, Zlataric' DK, Celebic' A (2012). Residual ridge atrophy in complete denture wearers and relationship with densitometric values of a cervical spine: a hierarchical regression analysis. Gerodontology. 29, 935-47.

[2] Tallgren A (2003). The continuing reduction of the residual alveolar ridges in complete denture wearers: A mixed-longitudinal study covering 25 years. Journal of Prosthetic Dentistry. 89, 427-35.

[3] Zlataric KD, Celebic A (2003). Mandibular bone mineral density changes in complete and removable partial denture wearers: A 6month follow-up study. International Journal of Prosthodontics. 16, $661-5$.

[4] Bianchi A, Sanfilippo F (2002). Osteoporosis: The effect on mandibular bone resorption and therapeutic possibilities by means of implant prostheses. International Journal of Periodontics and Restorative Dentistry. 22, 231-9.

[5] Watanabe PCA, Issa JPM, Oliveira TM, Monteiro SAC, Iyomasa MM, Regalo SCH (2007). Morphodigital study of the mandibular trabecular bone in panoramic radiographs. International Journal of Morphology. $25,875-80$

[6] Canger EM, Celenk PC (2012). Radiographic evaluation of alveolar ridge heights of dentate and edentulous patients. Gerodontology. 29 $17-23$.

[7] Jagadeesh MS, Patil RA, Kattimani PT (2013). Clinical evaluation of mandibular ridge height in relation to aging and length of edentulism. Journal of Dentistry and Medical Science. 3, 44-7.

[8] Şakar O, Sülün T, İspirgil E (2008). Correlation of the gonial angle size with residual ridge resorption in edentulous subjects. Balkan Journal of Stomatolgy. 12, 38-41.

[9] Vaishnav K, Shah D, Patel P (2010). A panoramic evaluation of the mandibular canal wall resorption in relation to Diabetes, Thyroid and Asthma in edentulous patients. Journal of International Oral Health. 2, 27-32.

[10]Spolyar JL (1987). Head positioning error in cephalometric radiography-an implant study. Angle Orthodontist. 57, 77-88.
[11] Atwood DA (1996). The problem of reduction of residual ridges. In: Winkler S, editor. Essentials of complete denture prosthodontics. 2nd edition. USA: Ishiyaku EuroAmerica Inc. p, 22-38.

[12]Kranjčić J, Stunić MK, Čelebić A, Komar D, Mehulić K, Vojvodić D (2013). Denture relining as an indicator of residual ridge resorption. Medicinski Glasnik. 10, 126-32.

[13]Ozola B, Slaidina A, Laurina L, Soboleva U, Lejnieks A (2011). The influence of bone mineral density and body mass index on resorption of edentulous jaws. Stomatologija Baltic Dental and Maxillofacial Journal. 13, 19-24.

[14] Saini V, Srivastava R, Rai RK, Shamal SN, Singh TB, Tripathi SK (2011). Mandibular ramus: An indicator for sex in fragmentary mandible. Journal of Forensic Science. 56, 13-8.

[15] Stramotas S, Geenty JP, Petocz, Darendeliler MA (2002). Accuracy of linear and angular measurements on panoramic radiographs taken at various positions in vitro. European Journal of Orthodontics. 24, 4352.

[16] Arifin AZ, Asano A, Taguchi A, Nakamoto T, Ohtsuka M, Tanimoto $\mathrm{K}$ (2005). Computer-aided system for measuring the mandibular cortical width on panoramic radiographs in osteoporosis diagnosis. Medical Imaging. 57, 813-21.

[17]López-Roldán A, Santolaya-Abad D, Gregori-Bertomeu I, GómezCastillo E, Selva-Otaolaurruchi E (2009). Bone resorption processes in patients wearing overdentures. A 6-years retrospective study. Journal of Clinical and Experimental Dentistry. 1, 24-30.

[18] Shahabi M, Ramazanzadeh B-A, Mokhber N (2009). Comparison between the external gonial angle in panoramic radiographs and lateral cephalograms of adult patients with Class I malocclusion. Journal of Oral Science. 51, 425-9.

[19]Huumonen S, Sipila K, Haikola B, Tapio M, Soderholm A-L, RemesLyly $T$ (2010). Influence of edentulousness on gonial angle, ramus and condylar height. Journal of Oral Rehabilitation. 37, 34-8.

[20] Al-Shamout R, Ammoush M, Alrbata R, Al-habahbah A (2012). Age and gender differences in gonial angle, ramus height and bigonial width in dentate subjects. Pakistani Oral and Dental Journal. 32, 81-7.

[21]Balcikonyte E, Balciuniene I, Alekna V (2003). Bone mineral density and radiographic mandibular body height. Stomatologija Baltic Dental and Maxillofacial Journal. 5, 137-40.

[22] Kordatzis K, Wright PS, Meijer HJ (2003). Posrerior mandibular residual ridge resorption in patients with conventional dentures and implant overdentures. International Journal of Oral and Maxillofacial Implants. 18, 447-52.

[23]Juodzbalys G, Wang HL, Sabalys G (2010). Anatomy of mandibular vital structures. Part II: Mandibular incisive canal, mental foramen and associated neurovascular bundles in relation with dental implantology. Journal of Oral and Maxillofacial Research. 1, 1-10.

[24] Al-Jabrah O (2011). Association of type 2 diabetes mellitus with the reduction of mandibular residual ridge among edentulous patients using panoramic radiographs. Open Journal of Stomatology. 1, 61-8.

[25] Wical KE, Swoope CC (1974). Studies of residual ridge resorption. Part I. Use of panoramic radiographs for evaluation of mandibular resorption. Journal of Prosthetic Dentistry. 32, 7-12.

[26] Amorim MM, Prado FB, Borini CB, Bittar TO, Volpato MC, Groppo FC (2008). The mental foramen in dentate and edentulous Brazilian's mandible. International Journal of Morphology. 26, 981-7.

[27]Ngeow WC, Dionysius DD, Ishak H, Nambiar P (2009). A radiographic study on the visualization of the anterior loop in dentate subjects of different age groups. Journal of Oral Science. 51, 231-7.

[28]Närhi TO, Ettinger RL, Lam EWM (1997). Radiographic findings, ridge resorption, and subjective complaints of complete denture patients. International Journal of Prosthodontics. 10, 183-9.

[29] Karaagaçlioglu L, Ozkan $P$ (1994). Changes in mandibular ridge height in relation to aging and length of edentulism period. International Journal of Prosthodontics. 7, 368-71.

[30]Zmysłowska E, Ledzion S, Jędrzejewski K (2007). Factors affecting mandibular residual ridge resorption in edentulous patients: a preliminary report. Folia Morphology. 66, 346-52.

[31]Kingsmill VJ (1999). Post-extraction remodeling of the adult mandible. Critical Review of Oral Biology and Medicine. 10, 384-404.

[32]D'Souza D (2012). Residual ridge resorption. Revisited. In: Virdi M, editor. Oral health care, 1st edition. Croatia: InTech Rijeka. P. 15-24.

[33]Xie Q, Narhi TO, Nevalainen JM, Wolf J, Ainamo A (1997). Oral status and prosthetic factors related to residual ridge resorption in elderly subjects. Acta Odontologia Scandinavia. 55, 306-13.

[34]Zarb GA, Bolender CL, Hickey JC, Carlsson GE (1990). Boucher's prosthodontic treatment for edentulous patients. 10th edition. St. Louis: CV Mosby. p. 3-27, 38-47, 468-83.

[35]Basker RM, Davenport JC (2002). Prosthetic treatment of the edentulous patient. 4rd edition. London. Blackwell Munksgaard Publishing Company. p. 1-51. 
[36]Schwartz-Dabney CL, Dechow PC (2002). Edentulation alters material properties of cortical bone in the human mandible. Journal of Dental Research. 81, 613-7. 